\title{
Um experimento criativo de Design Participativo para mobilidade urbana no Sul da Itália
}

\author{
A creative experiment of \\ Participatory Design for a new \\ urban mobility in Southern Italy
}

Pablo Marcel de Arruda Torres ${ }^{[1]}$

\begin{abstract}
Resumo: O processo de inovação é revertido para uma lógica de baixo para cima, onde todas as partes interessadas são convidadas a participar do processo de criação da inovação. O ambiente colaborativo torna-se uma força motriz por trás do uso de métodos abertos e participativos. Workshops de Co-Design são a principal ferramenta para fazer o Design Participativo funcionar, integrando a criatividade das partes interessadas no processo. Nesse sentido, realizou-se uma oficina criativa levando em consideração o contexto do sul da Itália, especialmente a realidade local de Nápoles. Devido a limitações de tempo, o desafio era projetar um workshop que durasse apenas um dia de trabalho. O workshop focou no processo criativo e na geração de ideias para confrontar imediatamente as necessidades identificadas, tornando o processo de design dinâmico, enxuto e eficiente, e usando a memória de curto prazo dos participantes.
\end{abstract}

Palavras-chave: Design Participativo. Workshop de Co-Design. Criatividade Coletiva. Mobilidade Urbana. 
Abstract: The innovation process is reversed for a bottom-up logic, where all stakeholders are invited to participate in the process of creating innovation. The collaborative environment becomes a driving force behind the use of open and participatory methods. Co-design Workshops are the main tool to make Participatory Design work, integrating stakeholders' creativity in the design process. In that sense, it was realized a creative workshop taking in consideration the Southern Italy context, especially the Naples local reality. Due to time constraints, the challenge was to design a workshop that lasted only a workday. The workshop focused on the creative process and generation of ideas to immediately confront the identified needs, thus making the design process dynamic, lean and efficient and using the participants' short-term memory.

Keywords: Participatory Design. Co-design workshop. Collective creativity. Urban mobility.

\section{INTRODUÇÃO}

Ao longo das últimas décadas, uma multiplicidade de atores sociais, incluindo instituições, empresas, organizações sem fins lucrativos e, acima de tudo, cidadãos de forma individual ou em associações, provaram que eles são capazes de agir fora dos modelos econômicos tradicionais. São grupos de pessoas e comunidades que atuam fora dos padrões de pensamento e comportamento dominantes, que reorganizam a forma como vivem em sua casa e em sua vizinhança. Elas mostram que é possível fazer as coisas de forma diferente e considerar o próprio trabalho, o próprio tempo e o próprio sistema de relações sociais em uma luz diferente, em busca de uma forma de bem-estar que é menos focada no produto e mais pensada em termos de bens comuns (ou seja, suas qualidades sociais e ambientais). Sobre esse aspecto, Grimaldi (2014, p.97) discorre que vivemos em uma dimensão em que promover o acesso a bens e serviços é mais relevante que possuí-los, onde a vivencia de experiências, relacionamentos, emoções, cultura e entretenimento é mais importante do que possuir coisas.

Projetar para o perfil deste novo usuário significa conceber e desenvolver soluções considerando e avaliando as capacidades das pessoas em termos de sensibilidade, competência e empreendedorismo, e projetando sistemas que Ihes permitam realizar o seu potencial, usando suas próprias habilidades e capacidades (Manzini, 2007, p.7). Essas soluções são concebidas e implementadas principalmente pelos 
atores envolvidos, que usam as suas capacidades pessoais, o seu conhecimento direto dos problemas a serem resolvidos e tecnologias existentes, muitas vezes de maneiras imprevistas.

À luz dos desafios globais que estamos enfrentando agora e da falta de capacidade das instituições e sistemas estabelecidos para resolvê-los satisfatoriamente, as respostas vêm apenas da sociedade e do pensamento predominante de que as pessoas são o elemento-chave para fazer a mudança acontecer. A cidadania ativa e o desejo de participação social no processo de mudança movem as pessoas e as respostas aos problemas enfrentados pela sociedade são criadas e implementadas. Neste cenário, um papel importante será desempenhado por uma série de iniciativas locais que, por várias razões, estão cada vez mais "aptas a quebrar os padrões consolidados e podem ser vistas como sinais promissores de novos comportamentos e novas formas de pensar" (Manzini, 2008 p. 61).

Um ponto fundamental da mudança é que estamos nos afastando de um velho paradigma técnico-econômico baseado na produção industrial, onde o conceito dominante de bem-estar está atrelado a artefatos que poderiam trabalhar para as pessoas, para nos aproximarmos de um novo paradigma baseado em informação, comunicação, colaboração e interação (Manzini, 2007; Perez, 2010). O momento de transição em que vivemos deve ser tratado como um "processo social de grande alcance" que deve ser conduzido de maneira aberta e flexível. Neste cenário, as iniciativas locais serão cada vez mais capazes de romper os padrões consolidados e ser vistos como "sinais promissores do novo comportamento e de novas maneiras de pensar" (Manzini, 2008, p. 61).

\section{UMA ABORDAGEM SOBRE DESIGN COLABORATIVO}

A partir dos anos 2000, o consumo de experiências gera novos tipos de relacionamento entre pessoas e artefatos a serem desenvolvidos. As pessoas são expostas a uma grande quantidade de informação, relacionando-se com o meio ambiente e o consumo de uma maneira mais racional e vi- 
venciando o mundo de uma maneira diferente. O objetivo do Design passa a ser criar significado para a vida das pessoas, usando seus próprios processos para estabelecer melhores conexões entre diferentes partes interessadas em problemas cada vez mais complexos. Por essa razão, a criatividade, a estratégia e a colaboração tornam o Design um processo centrado nas pessoas e focado na capacidade de inovação entre os diferentes stakeholders do projeto (Taranto, 2013).

Nesse processo, a interação entre as habilidades dos indivíduos torna-se a principal engrenagem de "um sistema onde conhecimento e criatividade podem ser encontrados de maneira difusa em toda a sociedade, e não limitados a conhecimento formal e empresas criativas" (Manzini, 2008, p. 70). Isso envolve relações iguais entre aqueles que produzem e aqueles que usam um produto e/ou um serviço, o que torna esses agentes mais eficazes na proposição de mudanças. A mudança é um novo conceito de bem-estar, onde as pessoas estão ativamente envolvidas e, de alguma forma, estão co-produzindo os resultados que desejam alcançar com seus próprios recursos intelectuais e práticos. Ou seja, um tipo de bem-estar em que o sujeito envolvido diante de um problema não é apenas "parte do problema", mas torna-se "parte da solução" (Burns et al., 2006, p. 25). Ou seja, o foco está na mudança do status do designer de um único criador e autor de um produto, para um tipo de agente capaz de aprimorar, instigar e promover o conhecimento na sociedade, criando e encontrando as melhores soluções para seus problemas através do desenvolvimento de produtos e/ou serviços (ibid).

Os interesses atuais dos designers em incluir pessoas no processo de design parecem resultar de uma expansão dos objetivos do Design para várias outras áreas tradicionais: serviços, lazer, saúde e bem-estar, hospitalidade, comunicação, distribuição de bens tangíveis e intangíveis, gerando efeitos sociais positivos e transformando as realidades existentes em outras mais desejáveis (Frascara, 2006). A partir deste ponto, inicia-se uma mudança de aspectos participativos de 
Design para formas intensivas de experimentação em que as fronteiras entre Design, produção e Marketing se tornam cada vez mais difusas e dispersas (Rizzo, 2009, p. 59).

O ambiente colaborativo torna-se uma força motriz por trás do uso de métodos abertos e participativos, abordando o Design a partir de temas como co-criação, cidadania, colaboração, participação social e inovação aberta. Burns et al. (2006, p. 18) também apontam que as soluções para os problemas complexos que enfrentamos hoje, como mobilidade, mudanças climáticas ou consequências do envelhecimento da população, dependem das decisões que as pessoas tomam em suas vidas cotidianas. Por isso, enfatizam a necessidade de envolver as pessoas nos processos criativos, porque elas podem gerar muitas ideias e sugestões, se oferecermos ferramentas e atividades para estimular a criatividade. Desse ponto de vista, o Design Participativo "é mais inspirador do que validar seus resultados" (Rizzo, 2009, p. 65).

A organização de uma sociedade em rede nos permite delinear como as pessoas participam de projetos colaborativos. Essas redes colaborativas são caracterizadas por motivações e formas de fazer capazes de catalisar um grande número de pessoas interessadas, organizá-las em grupos de pares, além de construir uma visão e direção comuns (Manzini, 2007, p.5). Essas redes geralmente surgem pela sinergia dos atores e se baseiam nos interesses de todas as pessoas envolvidas. No entanto, é um desafio gerenciar redes que atendem aos interesses de vários atores envolvidos no processo.

\section{SOBRE WORKSHOPS DE CO-DESIGN}

De acordo com Costa (2005), workshops de Co-Design foram desenvolvidos para integrar a criatividade das pessoas no processo de Design, desenvolvendo uma linguagem comum entre a equipe de projeto e os atores envolvidos. Jégou e Manzini (2003) argumentam que oficinas de Design geralmente envolvem exercícios de curta duração e caráter intensivo, feitos por pessoas interessadas em questões específicas, mas não neces- 
sariamente especialistas no mesmo tema. Seu objetivo principal é trazer uma multiplicidade de ideias, que sejam ao mesmo tempo originais e capazes de dar uma imagem do que "mentes novas" podem pensar e propor em um determinado tema.

Em comparação com outras aplicações, o método da oficina de Design demonstra relevância no confronto com algumas questões de projeto. Essa abordagem permite que os designers envolvidos atuem predominantemente como "antenas receptivas de ideias circulando sobre o tema", como catalisadores das ideias mais desafiadoras, repensando e adaptando-as aos ambientes locais, aprimorando-as com novas possibilidades e, finalmente, traduzindo-as em propostas sintéticas e comunicáveis, produzindo ao mesmo tempo resultados quantitativos e qualitativos (Lucca, 2011, p. 165).

Não há receita ou apenas uma forma de se realizar um workshop. No entanto, o lançamento de um briefing, a representação de algumas trajetórias para orientar a conceituação e o processo criativo de polinização são potencializados pelo uso de diferentes recursos (Cautela, 2007). Geralmente, no início de um workshop, os designers pedem aos participantes que se concentrem em situações reais ou mais recentes, e em atividades que, por algum motivo, considerem significativas sobre o conteúdo da atividade colaborativa. O compartilhamento das experiências recentes tem o papel de capturar e estimular a geração de ideias para melhorar as experiências das pessoas. Após a identificação de desejos e necessidades, é hora de produzir representações significativas (esboços, storyboards, mapas, cenários, etc.). Os participantes também criam protótipos de baixa fidelidade para visualizar e demonstrar os cenários que os participantes produziram (Rizzo, 2009, p. 133).

Assim, uma possível estrutura básica para realizar oficinas de Co-Design pode ter as seguintes etapas (ibidem):

- Fase 1: Narrativas - O objetivo desta etapa é produzir histórias a partir das quais as atividades da oficina de co-design serão iniciadas. Nesta fase: 
- Fase 2: Crie ideias, faça ações, produza protótipos - Esta fase tem como objetivo projetar cenários e construir protótipos de atividades futuras, a fim de representar idéias previamente imaginadas.

- Fase 3: Refletir e avaliar - O objetivo desta etapa é produzir reflexões críticas sobre as ideias geradas.

\section{PROJETO E APLICAÇÃO DO WORKSHOP}

O objetivo do workshop foi identificar uma abordagem de design participativo como uma forma inovadora de pensar alternativas para a mobilidade urbana sob a visão de estudantes. As atividades devem considerar o contexto de Nápoles, maior cidade do sul da Itália, famosa entre outras coisas por seu tráfego caótico. As ruas de Nápoles foram construídas na Idade Média e não são feitas para o tráfego de carros. Becos estreitos, lugares pequenos, falta de calçadas e muitos motoristas de ciclomotores fazem do trânsito napolitano uma das marcas da personalidade desta cidade.

Devido a limitações de tempo, o desafio foi projetar uma oficina que durasse apenas um dia de trabalho, com base na estrutura anteriormente apresentada por Rizzo (2009). Através de um processo simplificado, o workshop teve como objetivo lançar o desafio de projetar novas soluções para a mobilidade urbana e, através de métodos e ferramentas aplicadas no contexto napolitano, obter ideias de sistemas de Design que levassem em consideração as experiências pessoais dos participantes envolvidos.

Definiu-se a estrutura do workshop, e posteriormente métodos e ferramentas foram estabelecidos para serem usados e testados, cujas escolhas foram feitas baseadas principalmente no desafio de fazer um trabalho complexo em apenas um dia e na eficiência dos métodos para obter resultados no final do workshop. O tempo de cada etapa do projeto foi estabelecido a fim de ajudar a gerenciar o processo de Design. Desta forma, as atividades do workshop foram mescladas entre atividades individuais, exercícios em grupo e discussões com todos os participantes. 




Figura 1: Iniciando

discussões sobre o tema do workshop. Fonte: autor.

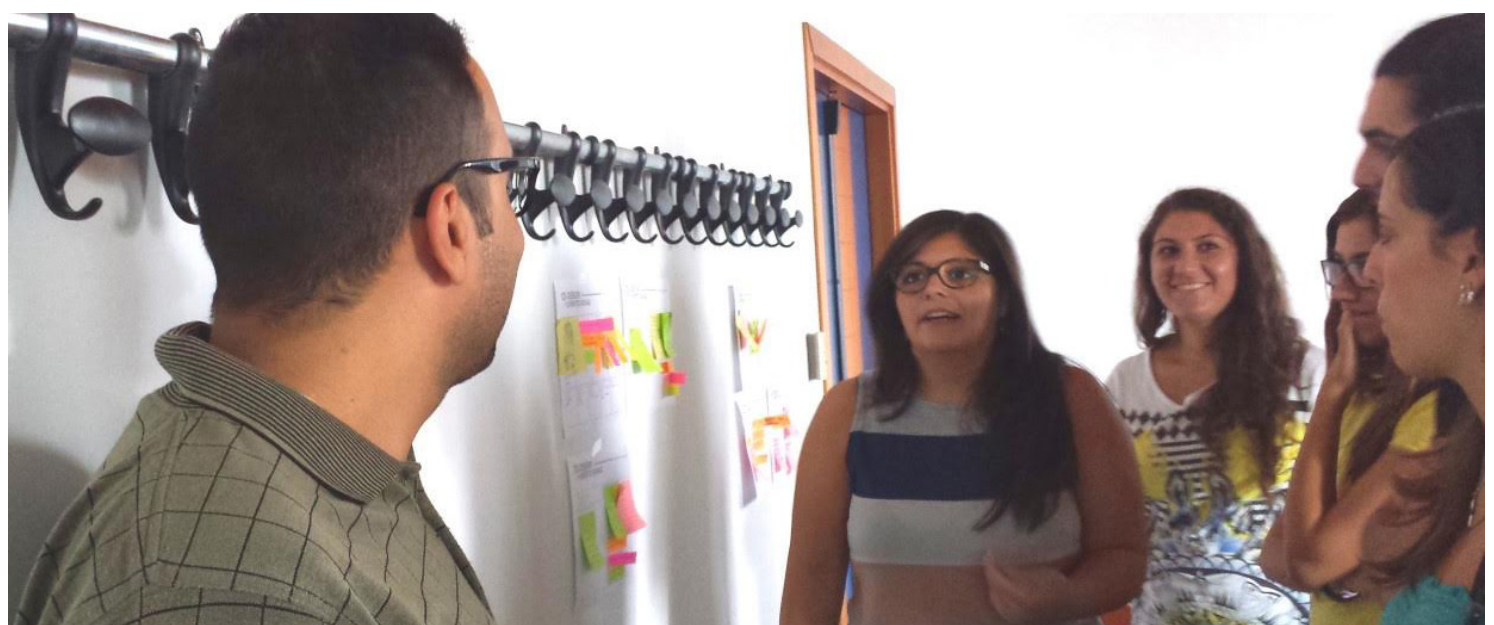

Figura 2: Apresentações dos resultados da manhã. Fonte: autor.

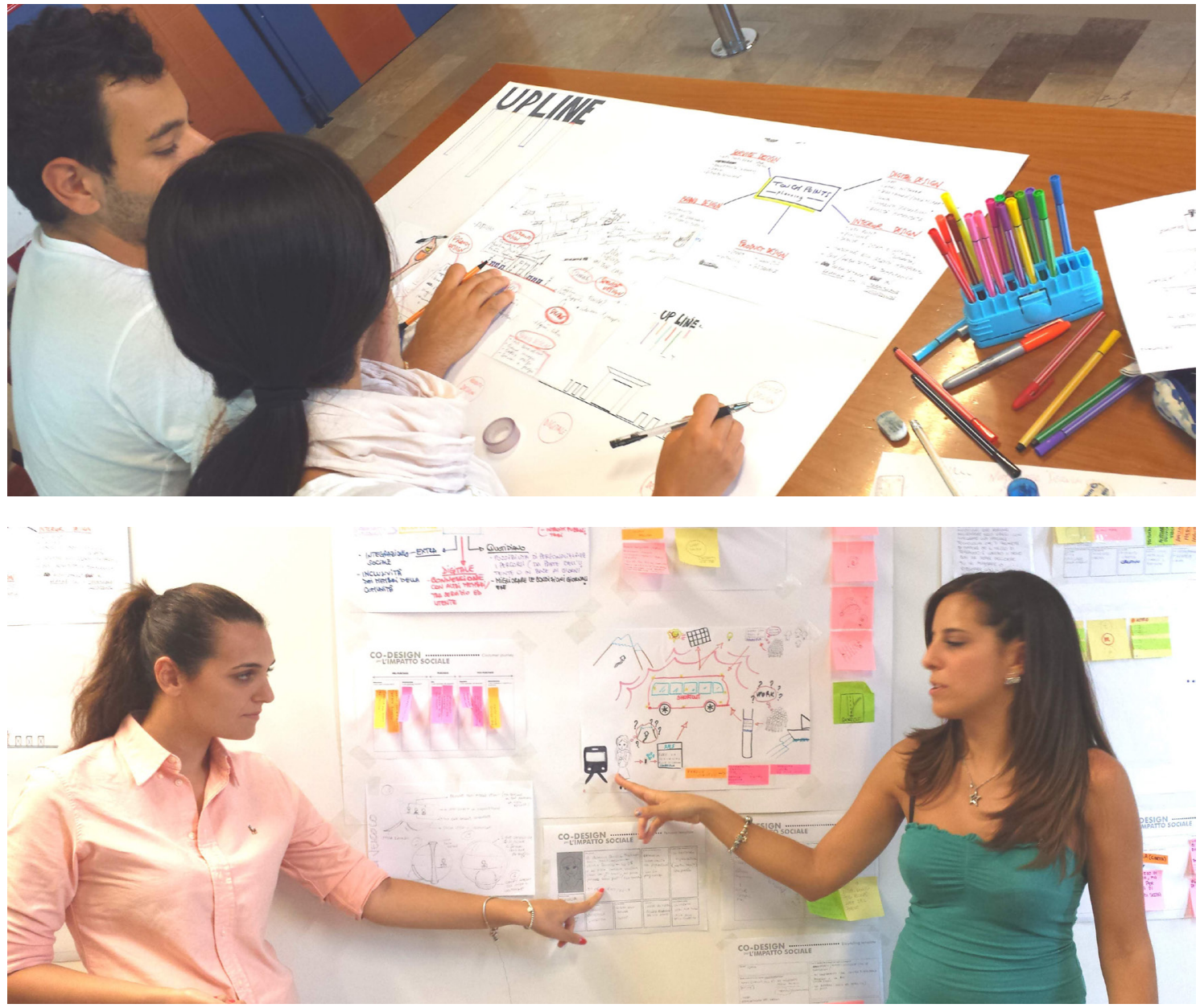

Figura 3: Fase Criativa em Progresso. Fonte: autor.

Figura 4: Apresentação dos resultados finais. Fonte: autor. 


\section{RESULTADOS DO WORKSHOP}

O primeiro grupo enfrentou o problema da falta de meios de transporte na conexão entre periferia e centro das cidades, principalmente abordando os pequenos municípios sem acesso a linhas de ônibus ou trem. Eles listaram como experiências negativas excesso de tráfego, suspensão de qualquer meio sem substituição, e longas esperas e lacunas entre uma linha e outra. Como solução (Figura 5), eles propuseram um transporte de zona, através de um veículo elétrico alternativo em que os usuários poderiam se locomover dentro da comunidade ou ir para a estação mais próxima de trem ou ônibus. A ideia é que os usuários solicitem o serviço através de um aplicativo, com rota personalizável e que pagasse apenas pela distância percorrida.

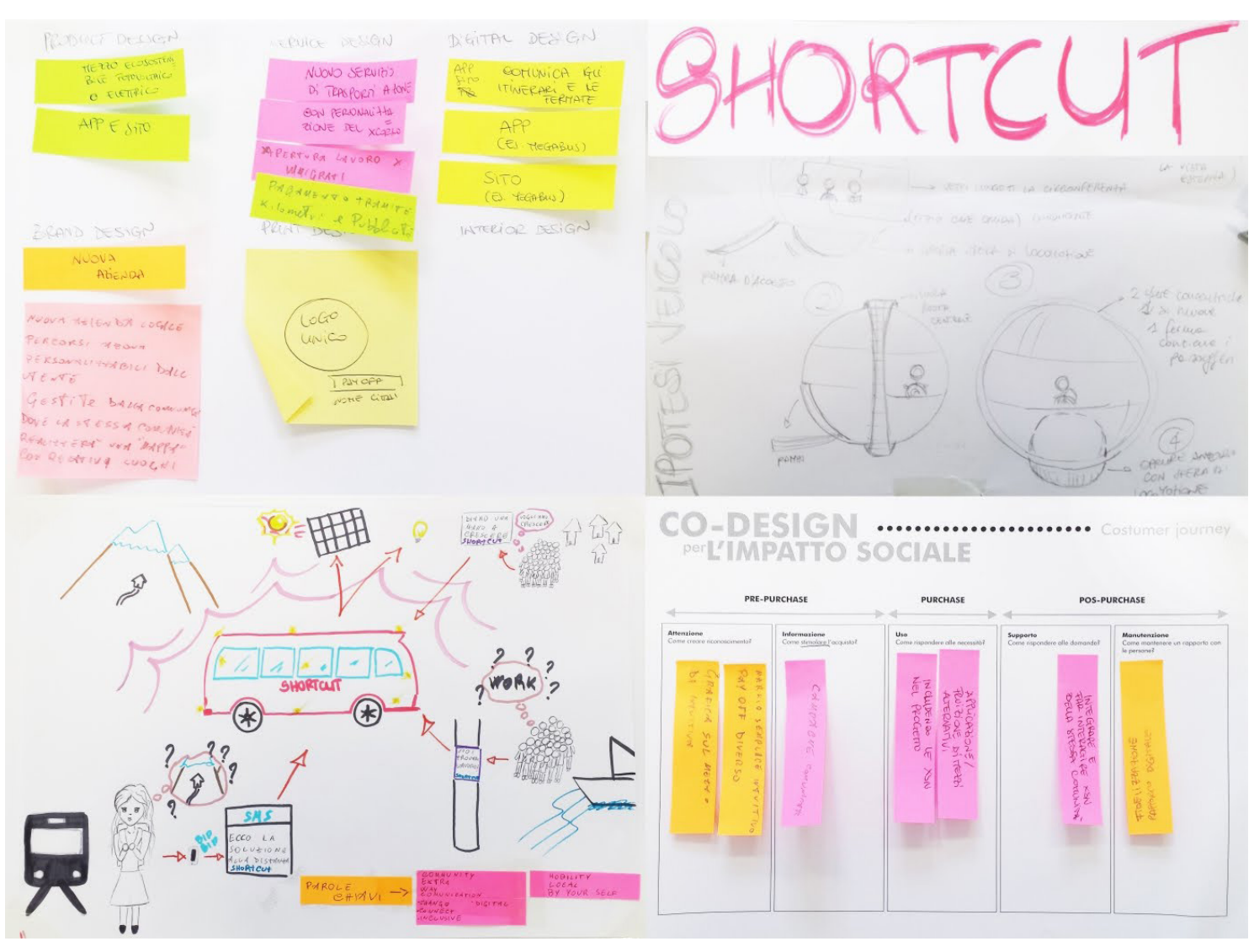

Figura 5: Resultados do workshop grupo 01. Fonte: autor. 
O segundo grupo optou por abordar o problema da mobilidade nos centros históricos das grandes cidades, abordando a falta de pontualidade dos meios e dos serviços de transporte público, o medo de os turistas se locomoverem em um local desconhecido e o alto preço dos serviços de táxi. A solução proposta (Figura 6) foi um veículo individual elétrico-cinético que funcionaria como alternativa aos já disponíveis. Seria um veículo compartilhado que aproveitaria os binários existentes para a promoção de passeios especializados, a fim de valorizar e redescobrir os centros históricos das grandes cidades. Assim, o serviço seria disponibilizado em infopoints distribuídos em diversos locais da cidade. O serviço também forneceria agendas, opções de pagamento, rotas de planejamento e comunidade por meio de um aplicativo móvel.

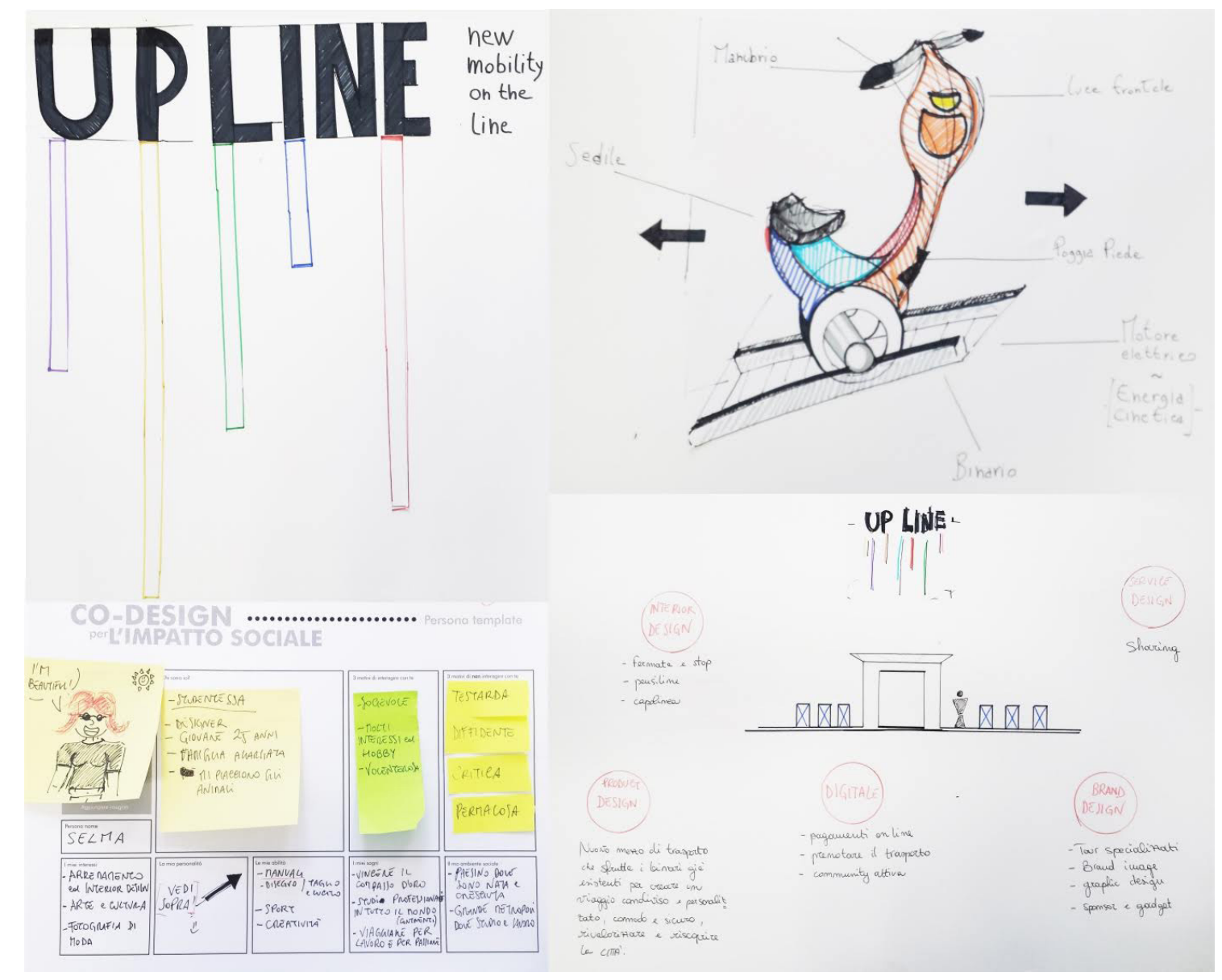

Figura 6: Resultados do workshop grupo 02. Fonte: autor. 
O grupo 3 abordou o problema de comunicação entre os meios de transporte e os usuários, e a falta de integração entre as informações de diferentes meios disponíveis em uma grande cidade. Destacaram como experiência negativa a falta de comunicação e pontualidade entre os diversos meios de transporte disponíveis. Como solução (Figura 7), o grupo propôs um sistema para planejamento de itinerários com informações alimentadas principalmente pela comunidade de usuários de serviços de uma cidade específica. O sistema consistiria de um dispositivo digital instalado em ônibus e trens urbanos, totens informativos nas paradas e um aplicativo móvel para informações portáteis, além de uma marca reconhecível. O sistema integraria informações de ônibus, trens urbanos, trens metropolitanos e intermunicipais, com horários programados e mapas em tempo real de linhas, avisos e mudanças nos serviços de transporte.

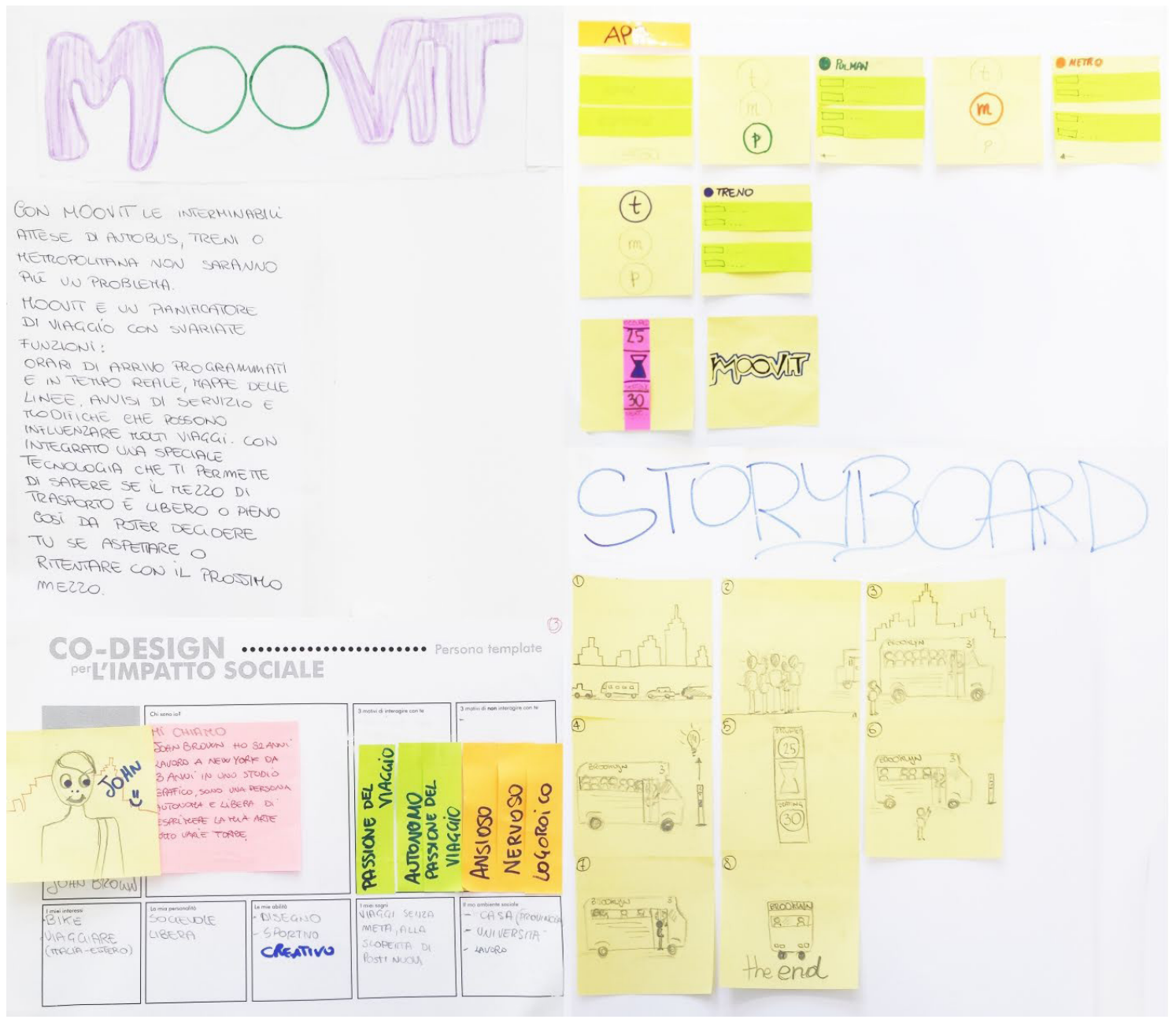

Figura 7: Resultados do workshop grupo 03. Fonte: autor. 
O último grupo abordou o problema da falta de controle dos bilhetes no transporte coletivo e a complementaridade entre os meios de transporte, principalmente considerando a taxa de evasão e passageiros sem passagem em transporte coletivo. Destacaram experiências de mobilidade limitada, falta de serviço noturno eficiente e complementaridade entre meios de transporte. Como solução (Figura 9), o grupo pensou um conceito inspirado na tradição napolitana do Caffé Sospeso. Trata-se de tomar um café num bar e deixar outro pagar por alguém que não pode pagar pelo café; como uma analogia, quem comprou uma bilhete de viagem poderia deixar um outro pago para alguém que não pode adquiri-lo. A ideia é que os compradores, além de ajudarem em uma causa social, pudessem aproveitar os parceiros da iniciativa, como universidades, museus, supermercados, empresas, etc. Os beneficiários seriam cadastrados em ONG's e associações sociais para que pudessem obter vantagem através de um cartão específico.

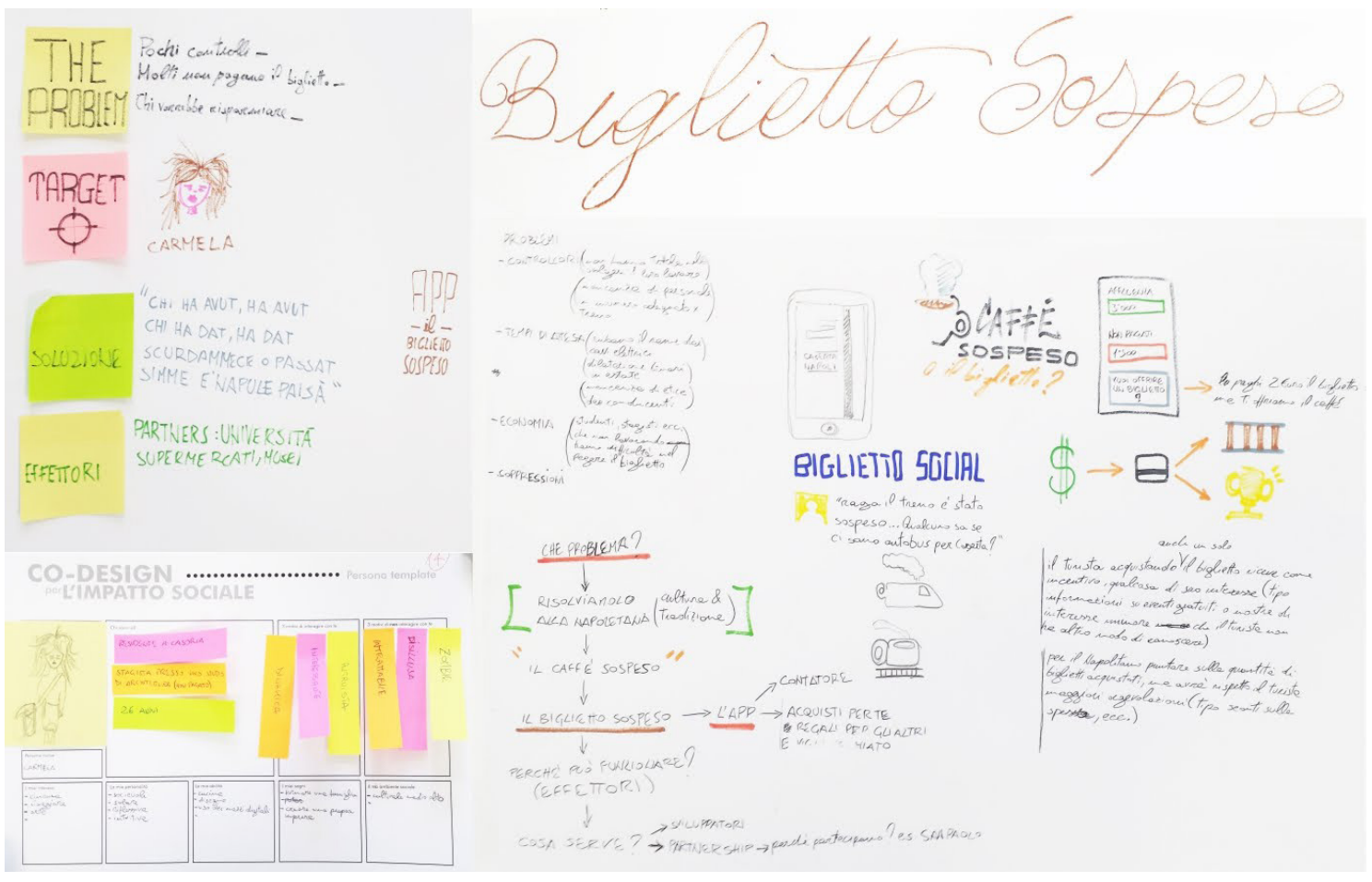

Figura 8: Resultados do workshop grupo 04. Fonte: autor. 


\section{CONCLUSÕES}

O workshop focou no processo criativo e na geração de ideias para confrontar imediatamente as necessidades identificadas, tornando o processo de projeto dinâmico, enxuto e eficiente, aproveitando para tal a memória de curto prazo dos participantes. As ferramentas aplicadas foram eficientes na organização do pensamento projetual, tornando o processo gerenciável e focado em soluções, muito úteis se considerarmos abordagens projetivas com não-designers.

A introdução de experiências pessoais e pontos de vista sobre os problemas enfrentados resultou em uma rica variedade de problemas identificados e soluções propostas, ou seja, cada grupo enfrentou um tipo diferente de problema, resultando em diferentes soluções. Para a geração de ideias era necessário considerar uma abordagem holística e sistêmica do Design, para que as soluções pudessem refletir inovações sociotécnicas com potencial de aplicação, e não apenas soluções isoladas.

Outro ponto a enfatizar foram os materiais utilizados durante toda a atividade. $\mathrm{O}$ uso de materiais simples e econômicos (papel, canetas, cola, fita, etc.) permitiu que os participantes retornassem para um Design não digital e analógico. Como a atividade exigia uma abordagem rápida e dinâmica, os materiais mais simples eram mais adequados para registrar informações imediatas e aumentar o fluxo de trabalho.

Para lidar com uma questão tão complexa como a mobilidade urbana, com suas diferentes nuances e possibilidades, obviamente os resultados de apenas um dia de trabalho não seriam capazes de refletir soluções prontas para serem aplicadas e implementadas com potencial suficiente para causar impacto na vida das pessoas. No entanto, o workshop mostrou que os métodos e ferramentas foram capazes de tornar a jornada de Design mais ágil, e em apenas um único dia de trabalho foi possível tirar quatro ideias diferentes para problemas de mobilidade urbana em um contexto local específico. 


\section{BIBLIOGRAFIA}

BURNS, C., COTTAM, H., VANSTONE, C., \&

WINHALL, J. RED PAPER 02: Transformation

Design. London: Design Council, 2006.

CAUTELA, C. Strumenti di Design Management [Design

Management Tools]. Milano: FrancoAngeli, 2007.

COSTA, F. Valutare l'usabilità: metodi di prova con utenti

e tecniche empiriche. Ergonomia progetto prodotto

[Ergonomics Design Product]. Milano: FrancoAngeli, 2005.

FRASCARA, J. 2006. "The dematerialization of design: a new profile for visual communication design". International

Council of Design. Disponível em: <http://www.ico-d.org/ connect/features/post/76.php>. Acesso em: 28 junho 2015.

GRIMALDI, P. Blur design: il branding invisibile ( $1^{\circ}$ ed.). Bologna: Fausto Lupetti Editore, 2014.

JÉGOU, F.; MANZINI, E. Collaborative

Services: Social innovation and Design for

Sustainability. Milano: Polidesign, 2003.

LUCCA, A. de S. 2011. Design e rilocalizzazione:

Strumenti progettuali per l'innovazione sostenibile nei paesi emergenti. Tese. Università luav di Venezia, 2011.

MANZINI, E. Design research for sustainable social innovation. In: MICHEL, R. (Org.), Design Research Now:

Essays and Selected Projects. Basel: Birkhäuser Basel, 2007

Design para a inovação social e

sustentabilidade: comunidades criativas, organizações

colaborativas e novas redes projetuais. (Cadernos do Grupo

de Altos Estudos; vol. I). Rio de Janeiro: E-papers, 2008. 
PEREZ, C. The financial crisis and the future of

innovation: a view of technical change with the aid of history. Working Papers in Technology Governance and Economic Dynamics, n. 28, Tallinn University of Technology, Estonia/ The Other Canon Foundation, Norway, 2010.

RIZZO, F. Strategie di Co-Design: teorie, metodi e strumenti per progettare con gli utenti [CoDesign strategies: theories, methods and tools to design with users]. Milano: FrancoAngeli, 2009.

TARANTO, F. “Del diseño participativo a la solución estratégica de problemas complejos: Una introducción al diseño de transformación". [From Participatory Design to the strategic solution of complex problems: An introduction to Transformation Design]. Revista i+Diseño, 8(5), 2013. 